\title{
Psychological Resilience and Burnout Levels in Occupational Therapists in Greece. An Epidemiological Nationwide Research
}

\author{
Aikaterini Katsiana1, Michael Galanakis², Vaggelis Saprikis³ ${ }^{3}$ Dimitrios Tsiamitros ${ }^{4}$, \\ Anastasios Stalikas $^{5}$ \\ ${ }^{1}$ Department of Occupational Therapy, University of Western Macedonia, KEPTSE, Ptolemaida, Greece \\ ${ }^{2}$ National Center for Public Administration \& Local Government, Athens, Greece \\ ${ }^{3}$ Department of Management Science and Technology, University of Western Macedonia, Kozani, Greece \\ ${ }^{4}$ Department of Electrical \& Computer Engineering Faculty of Engineering, University of Western Macedonia, Kozani, Greece \\ ${ }^{5}$ Department of Psychology, Panteion University of Social and Political Sciences, Athens, Greece \\ Email: galanakismichael@hotmail.com
}

How to cite this paper: Katsiana, A., Galanakis, M., Saprikis, V., Tsiamitros, D., \& Stalikas, A. (2021). Psychological Resilience and Burnout Levels in Occupational Therapists in Greece. An Epidemiological Nationwide Research. Psychology, 12, 84-106. https://doi.org/10.4236/psych.2021.121006

Received: November 28, 2020

Accepted: January 12, 2021

Published: January 15, 2021

Copyright (C) 2021 by author(s) and Scientific Research Publishing Inc. This work is licensed under the Creative Commons Attribution International License (CC BY 4.0)

http://creativecommons.org/licenses/by/4.0/

\begin{abstract}
Background: Occupational therapists (OT) practitioners are at risk of burnout given the complexity of the practice environment and the demands of the workload. Studies suggest that recognizing the symptoms of burnout and developing personal resilience as a preventive mechanism can help reduce the impact of or even prevent burnout. Purpose: The purpose of this study was to investigate psychological resilience and burnout in OTs and determine if psychological resilience can affect occupational burnout levels. Methods: 345 Occupational therapists (practitioners) from all over Greece (and Cyprus) participated in this study, and the tools used were the Connor-Davidson Resilience Scale (CD-RISC) for the measurement of psychological resilience and the Maslach Burnout Inventory (MBI) for the levels of Occupational Burnout. This survey was conducted in relation to specific demographic characteristics such as age, gender and years, location, work contexts, etc. Results: The results showed that $50 \%$ of the participants had no psychological resilience while $50 \%$ showed moderately high and high levels of burnout, and also showed that regardless of demographics, psychological resilience is not a statistically significant factor in dealing with Occupational Burnout. Conclusions: About one in two Occupational therapists (OTs), regardless of age, gender or professional experience, shows burnout, and measures need to be taken by the relevant health structures to prevent and treat the phenomenon before it leads to serious consequences. The study shows the multifactorial and complex nature of burnout and psychological resilience. More multidi-
\end{abstract}


mensional approaches are needed so as to suggest the corresponding effective interventions. It is suggested that recognition of burnout symptoms and coping strategies be included in the core curriculum along with strategies for strengthening psychological resilience, although it does not seem to be statistically significant to burnout, as it constitutes a psychoprophylactic factor for overall mental health and a great percentage of OTs does not have it.

\section{Keywords}

Resilience, Burnout, Occupational Therapists, Psychological Health

\section{Introduction}

Healthcare professionals, as well as clinicians that provide services to people in general, experience burnout quite often, and occupational therapists are no exception. In recent literature, the investigation of burnout and its consequences on the provision of services and the health professionals themselves is of great interest. Occupational therapists (OT) provide services, in the context of health, but also in various community structures (such as educational and private services) and are a high risk group for burnout. Several studies using the Maslach Burnout Inventory (MBI) questionnaire have investigated burnout experienced by occupational therapists in various countries (Balogun et al., 2002; Brown \& Pashniak, 2018; Escudero-Escudero et al., 2020; Gupta et al., 2012; Lloyd \& King, 2004; Maslach \& Jackson, 1981; Oddie \& Ousley, 2007; Painter et al., 2003; Rogers \& Dodson, 1988; Scanlan \& Still, 2013; Schlenz, Guthri, \& Dudgeon, 1995; Stephenson, 2019). The results showed that OT are one of the most endangered occupational groups while on the other hand little has been done in order to provide coping mechanisms and protection. It is important to be underlined that the nature of the job the OTs perform requires perfect psychological health and emotional stability on their behalf. Increased levels of stress and burnout definitely maximize the possibility of not reaching professional goals and customers' needs.

Burnout is a variable of interest in research because it is associated with job performance, reduced, organizational commitment, reduced job satisfaction, reduced care given to caretakers, resignations, increased absenteeism, and impact on personal health. The context for all settings of occupational therapy practice is both complex and energizing. Professional occupational therapists support individuals of all ages and groups of individuals, in a variety of contexts and situations, encouraging them to participate in meaningful occupations in natural settings. Moreover, occupational therapists work daily with different professionals in various multi-disciplinary teams, depending on the context in which they provide services. They need to be creative in designing project-focused interventions and they should also support access to and participation in all areas necessary for the functionality of the individuals. Given that occupational therapists usually work with people with illnesses and/or disabilities, they also face 
additional challenges in conjunction with legislation, educational challenges, professional and personal factors, as well as interactions between all these. In addition, they may take on managerial roles and other roles of responsibility, and there is usually a need for ongoing training on the complexity of addressing the different diagnostic needs of the individuals they provide services to (American Occupational Therapy Association, 2014). All of the above challenges can be stressful and increase the likelihood of burnout, so, the development of occupational and mental resilience is suggested in order to face them (Edward, 2005: p. 142; Stephenson, 2019).

Burnout according to Maslach is defined as "a syndrome of emotional exhaustion that occurs frequently among individuals who do "people work" of some kind." (as is the case with occupational therapy services), including depersonalization feelings towards both the recipients of services and their associates, a reduced sense of personal accomplishment and a sense of dissatisfaction (Maslach \& Jackson, 1981; Maslach \& Jackson, 1982). The definition includes the concepts of physical, mental and psychological exhaustion that result from constant contact with humans. The occupational burnout of occupational therapists could be defined as the physical, emotional, and psychological exhaustion that results from their loss of interest in providing the services that flow from their role (Hendrickson, 1979). Thus, the occupational therapist is characterized by lethargy and lack of concentration, confidence, humor and enthusiasm (McGee-Cooper, Trammell, \& Lau, 1990). Emotional exhaustion is associated with feelings of workload, chronic fatigue, and difficulty sleeping. This burnout that comes from the workplace is different from the classic depression because when not working the symptoms disappear. Emotional exhaustion is closely related to job performance and reduced productivity (Leiter \& Harvie, 1996), can be seen as a way to deal with work overload and is a predictor of depersonalization. Emotional exhaustion in health professionals, de facto leads to a depersonalization of others (Sofology, Efstratopoulou, \& Dunn, 2018).

Depersonalization entails loss of empathy for patients/clients and general interpersonal relations at work. Once depersonalization occurs, individuals feel less successful in their role and evaluate themselves less positively in their achievements (Laschinger, Leiter, Day, \& Glin, 2009). Some additional main reasons for the burnout of occupational therapists could be: the behavior of colleagues and clients in the work environment, heavy workload and working conditions as well as the lack of support from the State, the difficulties of professional identity (Scanlon et al., 2010) and of the role of OTs, lack of self-efficacy (Brouwers \& Tomic, 2000; Evers, Brouwers, \& Tomic, 2002), lack of motivation and competitiveness, OT recruitment and workforce issues and higher workload (Rodger et al., 2009; Scanlon et al., 2010), the continuous reforms of the legislative and regulatory system, the unsatisfactory financial rewards and the difficulty in managing stressful situations (Antoniou, Polychroni, \& Walters, 2000).

Dealing with employee burnout or the risk of burnout is the responsibility of both the individual and the organization (Waite, 2012). While occupational the- 
rapists run the risk of burnout, recognizing the above signs of burnout and developing personal resilience as a preventive mechanism seems to help reduce the impact or prevent it altogether (Scanlan \& Still, 2013; Stephenson, 2019).

Exploring the resilience of occupational therapists is important in light of the contribution it can make to a number of pathologies in the workplace and especially to burnout syndrome (Graber, Pichon, \& Carabine, 2015) as it is related to recovery from adversity and persistence in critical situations to return to a state of inner balance and health (Edward, 2005: p. 142). In addition, as far as we know this concept has not been explored much, concerning occupational therapists (Rivard \& Brown, 2019). In general, psychological resilience refers to the dynamic process of positive adaptation to adversity or to difficult conditions, trauma and exposure to risk factors. It refers to "a category of situations characterized by repetitive types of positive adaptation, in the context of significant adversity or even dangerous situations" (Luthar, 2006). This adaptation seems to involve both intra-individual/developmental and social mechanisms and dynamics (Graber, Pichon, \& Carabine, 2015). Psychological resilience, in addition to the process of positive recovery, is also characterized by the further development of the individual (Santos, 2012). The systematic study of psychological resilience usually focuses on those factors that "predict", facilitate or inhibit this recovery (Kimhi et al., 2018). According to various models, psychological resilience ultimately seems to depend on the balance between individual and ecological/environmental variables, but also between the so-called "protective" factors and the "risk factors". "Protective factors" include a range of developmental, intra-individual and social strategies. Most scholars converge on the view that psychological resilience is not the sole derivative of personality traits (Santos, 2012), but results from a combination of developmental, intra-individual, and social factors (Graber, Pichon, \& Carabine, 2015). In the recent literature it is stated that psychological resilience may fluctuate depending on the situation (situation-specific) (National Scientific Council on the Developing Child, 2015) and it is not a "result" or a final derivative, but a non-static, developmental process that evolves and unfolds as people themselves evolve in a changing environment (Santos, 2012). Strong personality traits and the existence of strong support networks seem to contribute to the enhancement of psychological resilience (Masten, 2001), while their absence is associated with an increased risk of "vulnerability" (Ong, Bergeman, Bisconti, \& Wallace, 2006). The study of psychological resilience is considered important in a wide range of variables from job and life satisfaction, to mental and physical health (Jackson, Firtko, \& Edenborough, 2007) and possibly, in the context of this research protocol, in this group of health professionals, that is in occupational therapists. The concept of psychological resilience in the workplace is associated not only with a lower chance of developing burnout syndrome (Edward, 2005: p. 142) but also with higher rates of satisfaction, commitment and efficiency (Youssef \& Luthans, 2007).

Psychological resilience is a dynamic process and can be cultivated, enhanced 
or even restored by looking at both individual and social components (Kimhi et al., 2018). At the intra-individual level, it seems to be related to the enhancement of positive emotions, strong personality traits and the cultivation of active management skills (Graber, Pichon, \& Carabine, 2015). At the societal level, building strong networks of help and support seems to shield psychological resilience (Kimhi et al., 2018). The importance of its investigation becomes even greater in the light of the contribution it can have to a number of pathogenic phenomena in the workplace and especially in relation to Occupational Burnout (Graber, Pichon, \& Carabine, 2015).

\section{Research Questions}

The purpose of this study was to investigate the levels of burnout and psychological resilience in occupational therapists in Greece and Cyprus and the interaction between the two variables.

The population of occupational therapists in Greece is an under-researched professional group for which the clarification of specific psychological relationships will be able to bring interventions and actions to ensure the best possible psychological results. The main research questions of the study were:

1) What are the Burnout Levels in OTs in Greece?

2) What are the Psychological Resilience Levels in OTs in Greece?

3) Does Burnout in OTs correlate to their Psychological Resilience?

4) How does Psychological Resilience differ in terms of the demographic characteristics of OTs (gender, age, how many years on the job, qualifications, marital status, place of residence)?

5) How does Burnout differ in terms of the demographic characteristics of OTs (gender, age, how many years on the job, qualifications, marital status, place of residence)?

6) Can a predictive model of burnout and psychological resilience be formulated based on the data?

\section{Methodology}

\subsection{Sample}

The research was conducted on a sample of 345 occupational therapists (OT) of which $64(18.6 \%)$ were men and $281(81.4 \%)$ women. The age distribution of the study sample was the following. 20 - 30 years: 137 (39.7\%), 31 - 40 years: 108 (31.3\%), 41 - 50 years: 69 (20\%), 51 - 60 years: $30(8.7 \%),>60$ years: $1(0.3 \%)$. Regarding the marital status of the participants, 141 (40.9\%) were married, 95 (27.5\%) were dating, 98 (28.4\%) were not married, 10 (2.9\%) were divorced, and $1(0.3 \%)$ was widowed. Of the individuals in the sample $132(38.3 \%)$ had children and $213(61.7 \%)$ did not. Regarding the work framework, 258 (74.8\%) OTs worked in the private sector and $87(25.2 \%)$ in the public sector. In terms of work responsibility 207 (60\%) were in a position of responsibility (boss/manager) and $138(40 \%)$ in a position of employee/subordinate. Regarding the public sec- 
tor, out of $87(25.2)$ people in the sample 40 (11.6\%) stated that they worked in Education, 3 (0.9\%) worked in Educational and Counseling Support Centers, 11 (3.2\%) in a rehabilitation center, 30 (8.7\%) in a hospital, 17 (4.9\%) in a mental health institution and $10(2.9 \%)$ in psychiatric care.

As for the recipients of the services 288 (83.5\%) OTs of the sample worked with children and adolescents, 48 (13.9\%) worked with adults, and only $9(2.6 \%)$ with seniors. In terms of working hours, 46 (13.3\%) worked 3 - 5 hours, 197 (57.1\%) 6 - 8 hours, 91 (26.4\%) 9 - 12 hours and 11 (3.2\%) more than 12 hours. In terms of working days per week, 4 (1.2\%) OTs worked 2 days a week, 14 (4.1\%) 3 days, 23 (6.7\%) worked 4 days, 248 (71.9\%) 5 days, 48 (13.8\%) 6 days and $8(2.3 \%) 7$ days. Regarding the years in present job, the OTs of the sample can be divided into 2 groups: 1 - 14 years: 275 (79.7\%) OTs and more than 14 years: $70(20.3 \%)$.

The sample was selected with special care in order to obtain data on a nationwide and Pancyprian scale. Their distribution by city/work area was Attica: 165 (47.8\%), Thessaloniki: 31 (9\%), Crete: 13 (3.8\%), Patras: 6 (1.7\%), Larissa: 18 (5.2\%), The rest of mainland Greece: 58 (16.8\%), The rest of island Greece: 22 (6.4\%), Cyprus: 30 (8.7\%).

The distribution of the sample in terms of professional experience was the following. 63 (18.3\%) OTs had 1 - 2 years of professional experience, $70(20.3 \%)$ 3 - 5 years, 52 (15.1\%) 6 - 10 years, 59 (17.1\%) 11 - 15 years, $44(12.7 \%) 16-20$ years, $47(13.6 \%) 21$ - 30 years and 10 (2.9) more than 30 years.

Regarding the educational level of the participants, 47 (13.6) had a second degree, 88 (25.5\%) had a master's degree, 6 (1.8\%) had a PhD and $204(59.1 \%)$ had only a first degree.

Finally it should be noted that all participants were in perfect psychological health meaning that they had not experienced any tragic life events in the past year as well as they were not currently ill or under medication of any kind.

\subsection{Tools}

\subsubsection{MBI (Maslach Burnout Inventory) (Maslach \& Jackson, 1986)}

The Maslach Burnout Inventory (MBI) (Maslach \& Jackson, 1986) was used to record the levels of burnout of OTs. The questionnaire was translated and adapted into Greek by Kokkinos (2006). The purpose of the questionnaire is to record the components of burnout on an emotional, behavioral and cognitive level. It includes 22 topics-suggestions that measure three dimensions of burnout, that is Emotional Exhaustion (EE), Depersonalization (DP) and a sense of Personal Accomplishment (PA). Participants are asked to rate the frequency with which a situation happens to them, using the Likert 7-point scale, which ranges from 0 (it never happens to me) to 6 (it happens to me every day). High scores on the EE and DP scales are considered to indicate high levels of burnout. In contrast, low scores on the efficiency scale are considered to indicate a high degree of burnout. The questionnaire has been checked for its validity in the Greek population, as well as for its reliability. The internal consistency reliability 
index of the questionnaire in our sample was Cronbach $\mathrm{a}=0.714$.

\subsubsection{CD-RISC (Connor-Davidson Resilience Scale), 2003}

Connor-Davidson Resilience Scale (CD-RISC) (Connor \& Davidson, 2003) was used to study Resilience. The scale consists of 25 self-referential statements of five ratings (0-Not at all true, 1-Rarely true, 2-Sometimes true, 3-Often true, 4-Almost always true) which have been structured based on the study of previous research and conceptual constructions related to the resilience, and correspond to the following five factors: 1) Individual Competence, High Criteria, and Perseverance; 2) Confidence in personal instinct, Long-suffering when facing a negative mood, and Empowered when dealing with Stress; 3) Positive Acceptance of Change and Safe Relationships; 4) Control; and 5) Spiritual Influences. The rating is based on how the respondents felt during the last month and the range of results ranges from 0 to 100 , with higher scores indicating greater resilience.

The weighting of the scale in both the general population and in clinical samples showed good internal consistency (Cronbach a $=0.89$ ) and also good control-re-control reliability (interrelation coefficient $=0.87$ ). The questionnaire used in the present study has been translated into Greek and weighted by Dimitriadou \& Stalikas (2012). The internal consistency reliability index of the questionnaire in our sample was Cronbach $\mathrm{a}=0.89$.

\subsubsection{Demographic Scale}

To answer the research questions, an accompanying demographic scale was constructed, which was provided along with the 2 above tools, at the end. The scale helped to collect data on gender, age category, marital status, having children, working in a private or public institution, holding a managerial position or not, the type of structure in which they worked, whether they work with children/adolescents or adults or seniors, working hours, working days per week, working years in the job, the work area, the amount of professional experience, relationship with colleagues and finally the existence of another degree apart from the basic OT to assess the educational level.

\subsubsection{Procedure-Issues of Ethics and Conduct}

The research took place in the period between November 2019-March 2020. The participants in the sample were identified and approached through synergy with the Panhellenic and Pancyprian Association of Occupational Therapists. Initially, a letter was sent to a total of $700 \mathrm{OTs}$, asking them to take part in the research, along with clarifications on its purpose and a consent form via e-mail. Of these, 345 responded (49.29\%). The questionnaires were completed anonymously and electronically through the Google forms platform. The average time to complete a questionnaire was 30 minutes. The survey was conducted to protect sensitive personal data based on the GDPR standard. The ethics and conduct issues were handled by the University of Western Macedonia. The researchers informed the participants about the purpose, objectives and use of the research 
results, through the information and consent form. The research was voluntary, posing no risk (Robson, 2011) and there was the option to leave at any time without any consequences. There was an algorithmic coding of the questionnaires for the protection of personal data and their security through the anonymity of the participants. Finally, the data and the results that emerged were not altered, they are honest and at the disposal of those involved.

\section{Results}

The statistical analysis and processing of the data was done with the program SPSS_Statistics_25. Initially, the sample distributions were calculated in terms of the main variables of the research, that is psychological resilience and burnout.

Regarding the first and the second research question, that is: the degree to which Greeks OTs experience Burnout and have Psychological Resilience, the averages and the standard deviations of the two concepts, both as a whole and in terms of their individual dimensions, were calculated. In addition, based on the results the participants in the sample were divided into 6 categories (zero existence of the characteristic, minimum existence, moderately low, moderately high, high and very high (see Tables 1-6).

Table 1. Mean and standard deviation of the sample regarding psychological resilience, emotional exhaustion, depersonalization, feeling of personal accomplishment and total burnout.

\begin{tabular}{cccccc}
\hline & $\begin{array}{c}\text { Psych. } \\
\text { Resilience }\end{array}$ & $\begin{array}{c}\text { Emot. } \\
\text { Exhaustion }\end{array}$ & Depersonalization & $\begin{array}{c}\text { Feeling } \\
\text { of PA }\end{array}$ & $\begin{array}{c}\text { Total } \\
\text { Burnout }\end{array}$ \\
\hline $\mathrm{N} \quad$ Valid & 345 & 345 & 345 & 345 & 345 \\
Mis. & 0 & 0 & 0 & 0 & 0 \\
\hline Mean & 93.75 & 37.54 & 21.31 & 26.54 & 96.32 \\
Median & 94.00 & 37.00 & 22.00 & 25.00 & 96.00 \\
Stand. Dev. & 11.15 & 6.84 & 3.08 & 5.85 & 5.97 \\
Variance & 124.35 & 46.84 & 9.50 & 34.22 & 35.63 \\
Minimum & 54.00 & 21.00 & 11.00 & 13.00 & 80.00 \\
Maximum & 118.00 & 55.00 & 29.00 & 46.00 & 113.00 \\
\hline
\end{tabular}

Table 2. Sample distribution regarding psychological resilience.

\begin{tabular}{ccccc}
\hline & Frequency & $\%$ & Valid \% & Cumulative \% \\
\hline Zero Resilience & 6 & 1.70 & 1.70 & 1.70 \\
Minimum Resilience & 49 & 14.20 & 14.20 & 15.90 \\
Medium Resilience & 117 & 33.90 & 33.90 & 49.90 \\
Satisfactory Resilience & 111 & 32.20 & 32.20 & 82.00 \\
Great Resilience & 57 & 16.50 & 16.50 & 98.60 \\
Maximum Resilience & 5 & 1.40 & 1.40 & 100.00 \\
Total & 345 & 100.0 & 100.0 & \\
\hline
\end{tabular}


Table 3. Sample distribution regarding emotional exhaustion.

\begin{tabular}{ccccc}
\hline & Frequency & $\%$ & Valid \% & Cumulative \% \\
\hline Zero & 1 & 0.30 & 0.30 & 0.30 \\
Minimum & 22 & 6.40 & 6.40 & 6.70 \\
Medium & 146 & 42.30 & 42.30 & 49.00 \\
High & 128 & 37.10 & 37.10 & 86.10 \\
Very High & 42 & 12.20 & 12.20 & 98.30 \\
Maximum & 6 & 1.70 & 1.70 & 100.0 \\
Total & 345 & 100.0 & 100.0 &
\end{tabular}

Table 4. Sample distribution regarding depersonalization.

\begin{tabular}{ccccc}
\hline & Frequency & $\%$ & Valid \% & Cumulative \% \\
\hline Zero & 1 & 0.30 & 0.30 & 0.30 \\
Minimum & 29 & 8.40 & 8.40 & 8.70 \\
Medium & 88 & 25.50 & 25.50 & 34.20 \\
High & 187 & 54.20 & 54.20 & 88.40 \\
Very High & 39 & 11.30 & 11.30 & 99.70 \\
Maximum & 1 & 0.30 & 0.30 & 100.00 \\
Total & 345 & 100.00 & 100.00 & \\
\hline
\end{tabular}

Table 5. Sample distribution regarding the feeling of personal accomplishment.

\begin{tabular}{ccccc}
\hline & Frequency & $\%$ & Valid \% & Cumulative \% \\
\hline Zero & 10 & 2.90 & 2.90 & 2.90 \\
Minimum & 167 & 48.40 & 48.40 & 51.30 \\
Medium & 101 & 29.30 & 29.30 & 80.60 \\
High & 56 & 16.20 & 16.20 & 96.80 \\
Very High & 11 & 3.20 & 3.20 & 100.00 \\
Maximum & 345 & 100.00 & 100.00 & \\
\hline
\end{tabular}

Table 6. Sample distribution regarding total burnout level.

\begin{tabular}{ccccc}
\hline & Frequency & $\%$ & Valid \% & Cumulative \% \\
\hline Zero & 6 & 1.70 & 1.70 & 1.70 \\
Minimum & 26 & 7.50 & 7.50 & 9.30 \\
Medium & 124 & 35.90 & 35.90 & 45.20 \\
High & 124 & 35.90 & 35.90 & 81.20 \\
Very High & 52 & 15.10 & 15.10 & 96.20 \\
Maximum & 13 & 3.80 & 3.80 & 100.00 \\
Total & 345 & 100.0 & 100.0 & \\
\hline
\end{tabular}


Based on the results of the analyses it seems that the average of OTs in terms of Psychological Resilience was 93.75 and the Standard Deviation. 11.15, the mean for Burnout was 96.32 and the S.D. 5.97 and in terms of the individual dimensions of Burnout, that is Emotional Exhaustion (EE), Depersonalization (DP) and the Feeling of Personal Accomplishment (PA), the averages and standard deviations of the sample were: Mean (EE) 37.54 and S.D. 6.84, Mean (DP) 21.31 and S.D. 3.08, Mean (PA) 26.54 and S.D. 5.58 respectively.

Regarding the categorization of the sample based on Tables 2-5, it seems that about $50 \%$ of the OTs do not have Psychological Resilience (Minor, minimal or moderately low) and 55\% show high Burnout (moderately high, high and very high) with the majority being between moderately high and high. Finally, regarding the dimensions of burnout, 51\% show moderately high, high or very high emotional exhaustion, 66\% show depersonalization behaviors and 51.30\% show a reduced feeling of Personal Accomplishment. The above results show in general that about one in two OTs shows moderate to high professional burnout, a fact that will be further commented in the discussion.

Regarding the third question of the research, regarding the relationship between psychological resilience and burnout, a correlation analysis between the two variables was performed, also examining the individual dimensions of burnout with psychological resilience (see Table 7).

Table 7. Correlation analysis between total burnout, emotional exhaustion, depsonalization, feeling of pa and psychological resilience.

\begin{tabular}{|c|c|c|c|c|c|c|}
\hline & & $\begin{array}{l}\text { Psych. } \\
\text { Resilience }\end{array}$ & $\begin{array}{c}\text { Em. } \\
\text { Exhaustion }\end{array}$ & Depers. & $\mathrm{PA}$ & $\begin{array}{c}\text { Total } \\
\text { Burnout }\end{array}$ \\
\hline \multirow{3}{*}{$\begin{array}{l}\text { Psychological } \\
\text { Resilience }\end{array}$} & Pearson Correlation & 1 & $-0.114^{*}$ & $0.214^{* *}$ & $-0.209^{\star *}$ & $0.185^{* *}$ \\
\hline & Sig. (2-tailed) & & 0.034 & 0.000 & 0.000 & 0.001 \\
\hline & $\mathrm{N}$ & 345 & 345 & 345 & 345 & 345 \\
\hline \multirow{3}{*}{$\begin{array}{l}\text { Emotional } \\
\text { Exhaustion }\end{array}$} & Pearson Correlation & $-0.114^{*}$ & 1 & $0.467^{* *}$ & $0.748^{\star *}$ & $0.655^{\star *}$ \\
\hline & Sig. (2-tailed) & 0.034 & & 0.000 & 0.000 & 0.000 \\
\hline & $\mathrm{N}$ & 345 & 345 & 345 & 345 & 345 \\
\hline \multirow{3}{*}{ Depersonalization. } & Pearson Correlation & $0.214^{* *}$ & $0.467^{* *}$ & 1 & $0.410^{* *}$ & $0.651^{\star *}$ \\
\hline & Sig. (2-tailed) & 0.000 & 0.000 & & 0.000 & 0.000 \\
\hline & $\mathrm{N}$ & 345 & 345 & 345 & 345 & 345 \\
\hline \multirow{3}{*}{ Feeling of PA } & Pearson Correlation & $-0.209^{* *}$ & $0.748^{* *}$ & $0.410^{* *}$ & 1 & 0.089 \\
\hline & Sig. (2-tailed) & 0.000 & 0.000 & 0.000 & & 0.098 \\
\hline & $\mathrm{N}$ & 345 & 345 & 345 & 345 & 345 \\
\hline \multirow{3}{*}{ Total Burnout } & Pearson Correlation & $0.185^{* *}$ & $0.655^{* *}$ & $0.651^{* *}$ & 0.089 & 1 \\
\hline & Sig. (2-tailed) & 0.001 & 0.000 & 0.000 & 0.098 & \\
\hline & $\mathrm{N}$ & 345 & 345 & 345 & 345 & 345 \\
\hline
\end{tabular}

*. Correlation statistically significant at the 0.05 level (2-tailed). ${ }^{* *}$. Correlation statistically significant at the 0.01 level (2-tailed). 
Based on the results of the correlation table (Table 7) it seems that there is a direct proportional statistically significant correlation between professional Burnout, Emotional exhaustion $(\mathrm{r}=0.651, p<0.01)$ and Depersonalization $(\mathrm{r}=$ $0.655, p<0.01)$. At the same time, a low intensity and statistically significant relationship between Burnout and Psychological Resilience is recorded ( $r=0.185$, $p<0.01)$. The link is on the verge of zero intensity and therefore we are adopting the null hypothesis for the third question of the research.

Although psychological resilience does not seem to be related to the levels of burnout, according to the literature it has psycho-prophylactic and overall positive effects on health. At the same time, burnout is an important factor of psychological risk in the workplace. Therefore, based on the data of our sample and within the context of the fourth and fifth research questions, we tried to determine whether specific demographic or other variables affect the levels of the 2 variables.

For this investigation, a series of Analyses of Variance were performed, most of which showed non-statistically significant relationships in terms of the development of psychological resilience and burnout. Gender, marital status, private or public employment, ownership of an occupational therapy center or being an employee, type of employer, whether services are provided to children, adults, or the elderly, daily working hours and working days per week, years of experience, the existence of a second degree, the area of employment do not seem to have a statistically significant effect on the two variables. In contrast to the other variables measured under the present research scheme, those that appeared to differentiate the sample in terms of levels of psychological resilience and burnout were post of head, childbearing, and relationship with colleagues.

The results of these variance analyses (see Tables 8-13) showed that OTs who have children have higher psychological resilience than those who don't, on a level of statistical significance $p=0.002$. At the same time, the childless OTs, in addition to lower psychological resilience, have higher levels of burnout than their peers who have children, as seen in Table 8 and Table 9.

Table 8. Descriptive statistics regarding psychological resilience and total burnout comparison between individuals with and without children in the sample.

\begin{tabular}{|c|c|c|c|c|c|c|c|c|c|}
\hline & & \multirow[t]{2}{*}{$\mathrm{N}$} & \multirow[t]{2}{*}{ Mean } & \multirow{2}{*}{$\begin{array}{c}\text { Stand. } \\
\text { Deviation }\end{array}$} & \multirow{2}{*}{$\begin{array}{l}\text { Stand. } \\
\text { Error }\end{array}$} & \multicolumn{2}{|c|}{$\begin{array}{l}\text { 95\% Confidence } \\
\text { Intervals }\end{array}$} & \multirow[t]{2}{*}{ Min. } & \multirow[t]{2}{*}{ Max. } \\
\hline & & & & & & Upper & Bottom & & \\
\hline \multirow{3}{*}{$\begin{array}{l}\text { Psych. } \\
\text { Resil. }\end{array}$} & With Children & 132 & 96.00 & 11.03 & 0.95 & 94.14 & 97.94 & 54.00 & 118.00 \\
\hline & Without Children & 213 & 92.30 & 11.01 & 0.75 & 90.83 & 93.81 & 62.00 & 117.00 \\
\hline & Total & 345 & 93.75 & 11.15 & 0.60 & 92.56 & 94.92 & 54.00 & 118.00 \\
\hline \multirow{3}{*}{$\begin{array}{c}\text { Total } \\
\text { Burnout }\end{array}$} & With Children & 132 & 80.52 & 13.32 & 1.15 & 78.22 & 82.81 & 39.00 & 114.00 \\
\hline & Without Children & 213 & 83.55 & 14.33 & 0.98 & 81.61 & 85.48 & 49.00 & 120.00 \\
\hline & Total & 345 & 82.39 & 14.01 & 0.75 & 80.91 & 83.87 & 39.00 & 120.00 \\
\hline
\end{tabular}


Table 9. Analysis of variance regarding the effect of having children on psychological resilience and total burnout.

\begin{tabular}{ccccccc}
\hline & & SS & df & MS & F & Sig. \\
\hline & Between Groups & 1128.68 & 1 & 1128.68 & 9.29 & 0.002 \\
Psych. Resilience & Within Groups & $41,648.37$ & 343 & 121.42 & & \\
& Total & $42,777.06$ & 344 & & & \\
& Between Groups & 748.82 & 1 & 748.82 & 3.84 & 0.050 \\
Total Burnout & Within Groups & $66,795.56$ & 343 & 194.73 & & \\
& Total & $67,544.38$ & 344 & & & \\
\hline
\end{tabular}

Table 10. Descriptive statistics regarding psychological resilience and total burnout comparison between individuals with managerial role and those without managerial role (managerial role/non managerial role).

\begin{tabular}{|c|c|c|c|c|c|c|c|c|c|}
\hline & & \multirow[t]{2}{*}{$\mathrm{N}$} & \multirow[t]{2}{*}{ Mean } & \multirow{2}{*}{$\begin{array}{c}\text { Stand. } \\
\text { Deviation }\end{array}$} & \multirow{2}{*}{$\begin{array}{l}\text { Stand. } \\
\text { Error }\end{array}$} & \multicolumn{2}{|c|}{$\begin{array}{l}\text { 95\% Confidence } \\
\text { Intervals }\end{array}$} & \multirow[t]{2}{*}{ Min. } & \multirow[t]{2}{*}{ Max. } \\
\hline & & & & & & Upper & Bottom & & \\
\hline \multirow{3}{*}{$\begin{array}{l}\text { Psych. } \\
\text { Resil. }\end{array}$} & MR & 207 & 95.42 & 10.46 & 0.72 & 93.98 & 96.85 & 62.00 & 118.00 \\
\hline & Non MR & 138 & 91.23 & 11.70 & 0.99 & 89.26 & 93.20 & 54.00 & 117.00 \\
\hline & Total & 345 & 93.74 & 11.15 & 0.60 & 92.56 & 94.92 & 54.00 & 118.00 \\
\hline \multirow{3}{*}{$\begin{array}{c}\text { Total } \\
\text { Burnout }\end{array}$} & MR & 207 & 82.75 & 14.38 & 0.99 & 80.78 & 84.72 & 39.00 & 120.00 \\
\hline & Non MR & 138 & 81.85 & 13.47 & 1.14 & 79.58 & 84.12 & 48.00 & 114.00 \\
\hline & Total & 345 & 82.39 & 14.01 & 0.75 & 80.91 & 83.87 & 39.00 & 120.00 \\
\hline
\end{tabular}

Table 11. Analysis of variance regarding the effect of having a managerial role on psychological resilience and total burnout.

\begin{tabular}{ccccccc}
\hline & & SS & df & MS & F & Sig. \\
\hline $\begin{array}{c}\text { Psych. } \\
\text { Resilience }\end{array}$ & Between Groups & 1447.51 & 1 & 1447.51 & 12.01 & 0.001 \\
& Within Groups & $41,329.54$ & 343 & 120.49 & & \\
Total & $42,777.06$ & 344 & & & 0.560 \\
Burnout & Between Groups & 66.85 & 1 & 66.85 & 0.34 & \\
& Within Groups & $67,477.53$ & 343 & 196.72 & & \\
\hline
\end{tabular}

Table 12. Descriptive statistics regarding psychological resilience and total burnout comparison between individuals based on the quality of their relationship with colleagues.

\begin{tabular}{|c|c|c|c|c|c|c|c|c|c|}
\hline & & \multirow{2}{*}{$\mathrm{N}$} & \multirow{2}{*}{ Mean } & \multirow{2}{*}{$\begin{array}{c}\text { Stand. } \\
\text { Deviation }\end{array}$} & \multirow{2}{*}{$\begin{array}{l}\text { Stand. } \\
\text { Error }\end{array}$} & \multicolumn{2}{|c|}{$\begin{array}{l}\text { 95\% Confidence } \\
\text { Intervals }\end{array}$} & \multirow{2}{*}{ Min. } & \multirow{2}{*}{ Max. } \\
\hline & & & & & & Upper & Bottom & & \\
\hline Psych. & Very Bad & 13 & 96.38 & 9.96 & 2.76 & 90.36 & 102.40 & 79.00 & 110.00 \\
\hline Resilience & Bad & 3 & 94.66 & 5.03 & 2.90 & 82.16 & 107.16 & 90.00 & 100.00 \\
\hline
\end{tabular}


Continued

\begin{tabular}{cccccccccc}
\hline & Neutral & 30 & 90.00 & 12.92 & 2.36 & 85.17 & 94.82 & 64.00 & 118.00 \\
& Good & 115 & 90.63 & 11.10 & 1.03 & 88.58 & 92.68 & 54.00 & 117.00 \\
& Very Good & 184 & 96.10 & 10.44 & 0.77 & 94.58 & 97.62 & 70.00 & 116.00 \\
& Total & 345 & 93.74 & 11.15 & 0.60 & 92.56 & 94.92 & 54.00 & 118.00 \\
\hline \multirow{3}{*}{ Total } & Very Bad & 13 & 78.38 & 16.08 & 4.45 & 68.66 & 88.10 & 39.00 & 108.00 \\
Burnout & Neutral & 30 & 82.86 & 13.59 & 2.48 & 77.78 & 87.94 & 57.00 & 114.00 \\
& Good & 115 & 84.05 & 15.13 & 1.41 & 81.25 & 86.84 & 51.00 & 120.00 \\
& Very Good & 184 & 81.40 & 13.19 & 0.97 & 79.48 & 83.32 & 48.00 & 118.00 \\
& Total & 345 & 82.39 & 14.01 & 0.75 & 80.91 & 83.87 & 39.00 & 120.00
\end{tabular}

Table 13. Analysis of variance regarding the effect of the quality of relationship between colleagues on psychological resilience and total burnout.

\begin{tabular}{ccccccc}
\hline & & SS & df & MS & F & Sig. \\
\hline & Between Groups & 2649.61 & 4 & 662.40 & 5.61 & 0.000 \\
Psych. Resilience & Within Groups & $40,127.44$ & 340 & 118.02 & & \\
& Total & $42,777.06$ & 344 & & & \\
\hline \multirow{2}{*}{ Total Burnout } & Between Groups & 1009.25 & 4 & 252.31 & 1.28 & 0.274 \\
& Within Groups & $66,535.13$ & 340 & 195.69 & & \\
& Total & $67,544.38$ & 344 & & & \\
\hline
\end{tabular}

The findings are similar in relation to holding a managerial or clerical position. Based on Table 10 and Table 11, OTs who hold a managerial position have higher psychological resilience compared to their colleagues who do not have a position of responsibility at a level of statistical significance $p=0.001$. However, holding a managerial position has nothing to do with burnout levels, as the results were not statistically significant.

Finally, a factor that affects the levels of psychological resilience seems to be the quality of the OTs' relationship with their colleagues (Table 12 and Table 13). Based on the data collected from the sample, the effect between peer relationships and psychological resilience is not linear. Specifically, OTs that have a very bad relationship with colleagues and OTs that have a very good relationship with them have statistically significant higher psychological resilience than OTs that have a mediocre relationship with their colleagues. This finding is surprising at first, but can be explained based on the literature on psychological resilience. More will be said in the discussion section.

Regarding the sixth question of the research, namely the creation of a predictive model for burnout and psychological resilience based on the variables of the research project, a linear regression analysis was performed, namely two separate regression analyses, one for burnout and another one for psychological resilience (see Tables 14-19). It is briefly stated that in order to explain the maximum 
Table 14. Regression analysis regarding the predictive power of total burnout, managerial role, colleagues relationship quality and children on psychological resilience.

\begin{tabular}{cccccccccc}
\hline & & & & & \multicolumn{5}{c}{ Change Statistics } \\
\cline { 6 - 10 } Model & $\mathrm{R}$ & $\begin{array}{c}\mathrm{R} \\
\text { Square }\end{array}$ & $\begin{array}{c}\text { Adjusted } \\
\mathrm{R} \text { Rquare }\end{array}$ & $\begin{array}{c}\text { Std. Error of } \\
\text { the Estimate }\end{array}$ & $\begin{array}{c}\text { R Square } \\
\text { Change }\end{array}$ & $\begin{array}{c}\mathrm{F} \\
\text { Change }\end{array}$ & df 1 & df 2 & $\begin{array}{c}\text { Sig. F } \\
\text { Change }\end{array}$ \\
\hline 1 & $0.335^{\mathrm{a}}$ & 0.112 & 0.102 & 10.56829 & 0.112 & 10.751 & 4 & 340 & 0.000 \\
\hline
\end{tabular}

a. Prediction factors: (Constant), total burnout, managerial role, colleagues relationship quality, children; $b$. Dependent variable: psychological resilience.

Table 15. Analysis of variance regarding the effect of total burnout, managerial role, colleagues relationship quality and children on psychological resilience.

\begin{tabular}{ccccccc}
\hline & Model & SS & df & MS & F & Sig. \\
\hline & Regression & 4802.884 & 4 & 1200.721 & 10.751 & $0.000^{\mathrm{b}}$ \\
1 & Residual & $37,974.177$ & 340 & 111.689 & & \\
& Total & $42,777.061$ & 344 & & & \\
\hline
\end{tabular}

a. Dependent variable: Psychological resilience; b. Predictive factors: (Constant), total burnout, managerial role, colleagues relationship quality, children.

Table 16. Regression indexes regarding the predictive power of total burnout, managerial role, colleagues relationship quality and children on psychological resilience.

\begin{tabular}{ccccccc}
\hline \multirow{2}{*}{ Model } & \multicolumn{2}{c}{$\begin{array}{c}\text { Unstandardized } \\
\text { Coefficients }\end{array}$} & $\begin{array}{c}\text { Standardized } \\
\text { Coefficients }\end{array}$ & t & Sig. \\
\cline { 2 - 4 } & B & Std. Error & Beta & & \\
\hline (Constant) & 66.092 & 9.946 & & 6.645 & 0.000 \\
Children & -3.920 & 1.173 & -0.171 & -3.342 & 0.001 \\
Managerial Role & -4.271 & 1.162 & -0.188 & -3.675 & 0.000 \\
Colleagues Relationship Quality & 1.533 & 0.603 & 0.130 & 2.543 & 0.011 \\
Total Burnout & 0.346 & 0.096 & 0.185 & 3.627 & 0.000 \\
\hline
\end{tabular}

a. Dependent variable: Psychological resilience.

Table 17. Regression analysis regarding the predictive power of psychological resilience, the type of clients, working days per week, years of experience, colleagues relationship quality, managerial role, years in current position, on total burnout.

\begin{tabular}{cccccccccc}
\hline & & & & & \multicolumn{5}{c}{ Change Statistics } \\
\cline { 6 - 9 } Model & $\mathrm{R}$ & $\mathrm{R}$ & Adjusted & Std. Error of \\
\cline { 6 - 9 } & & Square & R Square & the Estimate & $\begin{array}{c}\text { R Square } \\
\text { Change }\end{array}$ & $\begin{array}{c}\mathrm{F} \\
\text { Change }\end{array}$ & df 1 & df 2 & $\begin{array}{c}\text { Sig. F } \\
\text { Change }\end{array}$ \\
\hline 1 & $0.281^{\mathrm{a}}$ & 0.079 & 0.057 & 5.79651 & 0.079 & 3.592 & 8 & 336 & 0.001 \\
\hline
\end{tabular}

a. Predictive factors: (constant), psychological resilience, the type of clients, working days per week, years of experience, colleagues relationship quality, managerial role, years in current position. b. Dependent variable: total burnout.

possible dispersion of the two variables a variety of tests were performed with all possible combinations of available variables. However, it appeared that several variables did not add anything to the dispersion explained. Therefore, models with the maximum possible effect between the variables are presented. In this 
Table 18. Analysis of variance regarding the effect of psychological resilience, type of clients, working days per week, years of experience, colleagues relationship quality, managerial role, years in current position, on total burnout.

\begin{tabular}{ccccccc}
\hline & Model & SS & df & MS & F & Sig. \\
\hline & Regression & 965.476 & 8 & 120.685 & 3.592 & $0.001^{\text {b }}$ \\
1 & Residual & $11,289.451$ & 336 & 33.600 & & \\
& Total & $12,254.928$ & 344 & & &
\end{tabular}

a. Dependent variable: Total burnout; b. Predictive factors: (constant), psychological resilience, the type of clients, working days per week, years of experience, colleagues relationship quality, managerial role, years in current position.

Table 19. Regression indexes regarding the prediction of total burnout levels.

\begin{tabular}{cccccc}
\hline \multirow{2}{*}{ Model } & \multicolumn{2}{c}{$\begin{array}{c}\text { Unstandardized } \\
\text { Coefficients }\end{array}$} & $\begin{array}{c}\text { Standardized } \\
\text { Coefficients }\end{array}$ & $\mathrm{t}$ & Sig. \\
\cline { 2 - 4 } (Constant) & $\mathrm{B}$ & Std. Error & Beta & & \\
\hline Managerial Role & 0.6916 & 4.096 & & 21.929 & 0.000 \\
Age & -0.414 & 0.339 & -0.066 & -1.221 & 0.223 \\
Colleagues Relationship Quality & -1.864 & 0.650 & -0.308 & -2.866 & 0.004 \\
Type of Clients & -1.023 & 0.713 & -0.078 & -1.434 & 0.153 \\
Working Days per Week & -0.286 & 0.424 & -0.036 & -0.675 & 0.500 \\
Years in current position & 0.039 & 1.009 & 0.003 & 0.039 & 0.969 \\
Years of Experience & 1.277 & 0.368 & 0.381 & 3.473 & 0.001 \\
Psychological Resilience Total & 0.100 & 0.029 & 0.188 & 3.423 & 0.001 \\
\hline
\end{tabular}

${ }^{a}$ Dependent variable: Total burnout.

light, the first model (Tables 14-16) examines the effect of the variables: burnout, having children, holding a position of responsibility and the quality of the relationship with colleagues, in terms of predicting levels of psychological resilience. The second model (Tables 17-19) presents the effect of the variables: psychological resilience, recipients of services, working days per week, years in the current position, quality of relationships with colleagues, holding a position of responsibility, age and total years of professional experience, in terms of predicting burnout levels.

Based on the results of the analyses, the best/strongest model that can be formulated in terms of psychological resilience includes Occupational Burnout, Holding a position of responsibility, Quality of relationships with colleagues and Presence of children. These factors predict $11.20 \%$ of the variation of the phenomenon. The percentage is not high but it is the highest that the variables of the present study can predict.

In terms of burnout the best/strongest model that can be formulated includes Psychological Resilience, Recipients of Services, Working Days per week, Years in the current position, Quality of relationship with colleagues, Holding a posi- 
tion of responsibility, Age and Total years of professional experience. These factors predict $8 \%$ of the variation of the phenomenon. Again, this is not high but it is the highest based on the variables of the present research planning.

\section{Discussion}

The present research was carried out on a wide sample of occupational therapists, on a nationwide scale (including Cyprus) in order to examine the degree of burnout, psychological resilience and the role of psychological resilience in reducing burnout. According to the results of the first and second research question of the present study, it appears that a percentage of about $50 \%$ of OTs show high occupational burnout and about $50 \%$ do not have psychological resilience. These findings can be interpreted on the basis of the complex and demanding role of OTs and the difficulties in achieving their goals. The percentage seems high and certainly concerns the mental health of these health professionals and requires the immediate activation of institutions and the creation of a protective framework. This percentage is lower than the one in the study of Escudero-Escudero et al. (2020) concerning OTs in Spain (63.5\%) but higher than what Reis et al. (2018) found regarding OTs in Portugal (44\%) and Poulsen et al. (2014) in the UK (32.54\%). Previous research conducted in Greece and Cyprus (Anyfantis et al., 2020) also shows high levels of burnout among occupational therapists but unfortunately the results cannot be compared, whether the rate has increased or remained the same, because the measurements were made with different tools. Regarding the dimensions of burnout, the results show that the participants OTs, show greater depersonalization (DP) instead of emotional exhaustion (EE) as in other studies (Brown \& Pashniak, 2018; Brown \& Pranger, 1992; Edwards \& Dirette, 2010; Gupta et al., 2012), in contrast to some others who argue that OTs are protected from depersonalization due to the nature of their profession (Painter et al., 2003; Rogers \& Dodson, 1988). DP levels are higher than those reported in other studies (Escudero-Escudero et al., 2020; Gupta et al., 2012). These differences in outcomes may be due to changes in the profession of OTs and in education, increasing demands and increased stress in healthcare over time, and different environments in the workplace of different countries. The sense of low professional effectiveness, PA (personal accomplishment) is also higher than in all other studies.

However, although at first sight, and by the reading rates, burnout seems to be associated with lack of psychological resistance, the correlation analysis that was performed as to the third question of the research has not confirmed this hypothesis. On the contrary, an almost zero and non-statistically significant relationship was found. In practice, this means that in our sample OTs with high resilience can have high fatigue and vice versa. This finding is not in accordance with literature to date, in other health professional sectors and in teachers. The concept of psychological resilience is promoted internationally as a pillar of mental health and treatment of psychopathology, while several studies link it to the treatment of negative phenomena such as work stress. In this case, however, 
the seemingly zero correlation of psychological resilience with burnout shows that this phenomenon may be more complex and the increase or decrease of its levels is more multifactorial. One interpretation that could be given is that burnout is not so much a phenomenon of stress accumulation as a phenomenon of frustration and denial of expectations. That is, psychological resilience affects stress as an antidote, as the latter contains feelings of pressure and discomfort, while it does not affect burnout at all, as the latter contains mostly feelings of sadness, grief and frustration. Professional occupational therapy studies in particular have highlighted that some important burnout-related factors are issues very different from those concerning other health professionals, such as occupational identity issues, poor recognition and knowledge of the essential role of this profession by others (especially interdisciplinary professionals). And lack of supervision and support (Edwards \& Dirrete, 2010). This issue should be further researched and enriched in terms of other dimensions-factors in the workplace.

Subsequently, studying psychological resilience and burnout (research questions 4 and 5) it was found that of all the research variables there were specific ones that show a greater and statistically significant effect. More specifically, in terms of psychological resilience, OTs with children had higher psychological resilience, as well as OTs with a position of responsibility/head in their organization. The above can be interpreted as follows. Having children can act as a balancing factor in the pressures and frustrations of the work environment. Moreover, the existence of children can lead to greater mobilization and consequently greater psychological resilience. Finally, an interesting finding on psychological resilience was the effect of the quality of relationships with the colleagues. The relationship, however, is not linear as it was expected. A good relationship with the colleagues is associated with high levels of psychological resilience; however, the very bad relationship with colleagues has the same effect. On the contrary, a moderate, neutral or simply tolerable relationship with colleagues leads to lower levels of psychological resilience. The interpretation that can be given to the one end of the relationship is obvious. In the background of a very good relationship with the colleagues a social support network is created, on the benefits and value of which there is huge literature. As to the beneficial effect of a very bad relationship with the colleagues in terms of the levels of psychological resilience, what can be argued is that it hardens the employee and places him in a pattern of survival and readiness that may be related to the development of psychological resilience. This finding too is very innovative, rare and unexpected, and definitely needs further research and empirical documentation.

Regarding burnout, the analysis showed statistically significant effects only as regards the presence of children. Specifically, those who do not have children experience greater occupational burnout compared to those who have children and the same is true in the study of Escudero-Escudero et al. (2020) in the Spanish National Institutions. This finding may be interpreted on the basis of existential reasons but also on the base of a balance between professional and personal life. In the study of Gupta et al. (2012) maintaining a professional/personal 
balance and spending time with family are referred to as coping strategies for OTs who experience burnout. The presence of children seems to work in balance with the pressures and frustrations of work, and this shows the differentiating effect of the family, which is arguably a stronger supportive framework in relation to the group of colleagues or friends. Working hours and days, working in a public or private institution as well as years in office and years of experience as a whole do not seem to be related to the burnout of OTs in the present study, as supported by other studies (Painter et al., 2003; Brown \& Pashniak, 2018). Some studies argue that burnout is the disease of expectation and mainly affects young people in the profession, as shown by the study of Brown and Pashniak (2018) in OTs, especially when they are related to the provision of services to third parties and have high expectations for their position and role. The fact that this was not confirmed in the present study as well as the fact that the other demographic variables do not appear to be related to burnout, is consistent with the results of Escudero-Escudero et al. (2020), Edwards and Dirrete (2010), by Lloyd et al. (2002). In addition, the largest percentage of participants OTs in the present study $(67.8 \%)$ worked in private and the rest in public, very few in rehabilitation centers $(3.2 \%)$ and in psychiatric healthcare $(2.9 \%)$, so it was not possible to compare burnout levels in relation to these frameworks and the others, in which previous studies show that these OTs have higher burnout levels (Painter et al., 2003). Also the existence of a large percentage of OTs in the sample with high and very high occupational fatigue but also the inability to attribute this fatigue to the variables studied, testifies to the multifactorial nature of the phenomenon and highlights the need for a multifaceted approach and replanning with more variables.

The above interpretation concerning both burnout and psychological resistance applied to the sixth question of the research. The regression analyses showed predictive power with a low rate of explained dispersion and a small number of factors in relation to the total contained in the research planning. Specifically, the model suggested for psychological resilience includes Burnout, holding a position of responsibility, the quality of relationships with colleagues and having children, and explains $11.20 \%$ of the variation of the phenomenon. Respectively, in terms of burnout the model proposed includes Psychological Resilience, Recipients of services, Working days per week, Years in the current position, Quality of relationship with colleagues, Holding a position of responsibility, Age and Total years of professional experience, and explains $8 \%$ of the variance of the phenomenon. These percentages show the degree of complexity and the multifactorial structure of the two phenomena and are orienting us towards different and more developed research planning in the future.

Regarding the limitations of the research, the response rate to the completion of the questionnaires could be mentioned in the first place, which ranged around $50 \%$, while ideally it should be close to $75 \%$. Furthermore, the data collection was done with self-report questionnaires and this possibly affected the completion towards the socially desirable. Another variable that should be mentioned is 
the data collection process that was done simultaneously and at a time point, which may have affected the completion. In addition, the data collection period coincided with the outbreak of Covid-19 and the quarantine measures imposed throughout the country. The outbreak of the disease and the repressive measures appear to have affected the overall image and may partially explain the lack of association between psychological resilience and burnout recorded in our sample. Finally, the absence of measurement of other variables can be recorded as a limitation of the research. related to both psychological resilience and burnout. Such variables are: expectations, organizational culture, heavy workload, a subjective sense of justice in the context, the relationship with the boss., the balance of positive and negative emotions, the existence of previous psychopathology, financial gains, previous serious life events and especially for OTs a sense of professional identity, recognition by other professionals, information and knowledge of occupational therapy and practice focused on work.

Despite the limitations, the importance of research and findings is great. First of all, it is the first nationwide research adapted to the special population of the OTs in terms of measuring the levels of psychological resilience and studying its relationship with burnout. The fact that based on the measurements $50 \%$ of OTs show high to very high burnout is important as well. This should concern the National Association and the competent health structures in terms of prevention and treatment of the phenomenon before it leads to serious consequences. The research also emphasizes the multifactorial and complex nature of the phenomenon of both burnout and psychological resilience. It seems that more multidimensional approaches are needed in order to analyze the phenomena in their essence, in different health sectors and to be able to access effective interventions. The fact that burnout does not depend on age, gender or number of years in the job is also important. This means that anyone can be potential victims or patients and therefore the need to find prevention mechanisms is imperative.

Regarding suggestions and directions for future research, it is suggested that this research be repeated in a year from today and in a larger sample in order to calculate comparative results and demonstrate the extent of the phenomenon. Secondly, it is suggested that the research planning be enriched, by adding other variables such as the relationship with the boss, workload, financial earnings, stress, positive and negative emotions, social support, supervision, sense of professional identity and recognition by others, which may be able to explain the variability of the phenomena more broadly An important direction of new research could be the evaluation of the effect of specific interventions in the real work environment and the most immediate investigation of their effect on the occupational burnout levels of occupational therapists.

Finally, it would be useful to include the two variables of the study, that is psychological resilience and burnout, in the core curriculum so that future occupational therapists will be able to recognize the symptoms and characteristics of burnout and psychological resilience and gain an important toolbox to enhance their psychological health, prevent and deal with negative occupational 
phenomena, and finally achieve better professional performance and personal development (Ashby, Ryan, Gray, \& James, 2013).

\section{Conflicts of Interest}

The authors declare no conflicts of interest regarding the publication of this paper.

\section{References}

American Occupational Therapy Association (2014). Occupational Therapy Practice Framework: Domain and Process (3rd ed.). American Journal of Occupational Therapy, 68, S1-S48. https://doi.org/10.5014/ajot.2014.686S01

Antoniou, A. S., Polychroni, F., \& Walters, B. (2000). Sources of Stress and Professional Burnout of Teachers of Special Educational Needs in Greece. International Special Education Congress, Manchester, 24-28 July 2000.

Anyfantis, I. D., Psychouli, P., Varianou-Mikelidou, C., \& Boustras, G. (2020). Cross-Sectional Survey on Burnout and Musculoskeletal Disorders in Greek and Cypriot Occupational Therapists. Occupational Therapy in Mental Health, 36, 291-302. https://doi.org/10.1080/0164212X.2020.1779630

Ashby, S. A., Ryan, S., Gray, M., \& James, C. (2013). Factors That Influence the Professional Resilience of Occupational Therapists in Mental Health Practice. Australian Occupational Therapy Journal, 60, 110-119. https://doi.org/10.1111/1440-1630.12012

Balogun, J. A., Titiloye, V., Balogun, A., Oyeyemi, A., \& Katz, J. (2002). Prevalence and Determinants of Burnout among Physical and Occupational Therapists. Journal of Allied Health, 31, 131-139.

Brouwers, A., \& Tomic, W. (2000). A Longitudinal Study of Teacher Burnout and Perceived Self-Efficacy in Classroom Management. Teaching and Teacher Education, 16, 239-253. https://doi.org/10.1016/S0742-051X(99)00057-8

Brown, C. A., \& Pashniak, L. M. (2018). Psychological Health and Occupational Therapists: Burnout, Engagement and Work Addiction. Work, 60, 513-525. https://doi.org/10.3233/WOR-182759

Brown, G. T., \& Pranger, T. (1992). Predictors of Burnout for Psychiatric Occupational Therapy Personnel. Canadian Journal of Occupational Therapy, 59, 258-267. https://doi.org/10.1177/000841749205900507

Connor, K. M., \& Davidson, J. R. (2003). Development of a New Resilience Scale: The Connor Davidson Resilience Scale (CD-RISC). Depress Anxiety, 18, 76-82. https://doi.org/10.1002/da.10113

Dimitriadou, D., \& Stalikas, A. (2012). Connor-Davidson Resilience Scale (CD-RISC). In A. Stalikas, S. Triliva, \& P. Roussi (Eds.), Psychometric Instruments in Greece (2nd ed., p. 717). Athens: Pedio.

Edward, K.-L. (2005). The Phenomenon of Resilience in Crisis Care Mental Health Clinicians. International Journal of Mental Health Nursing, 14, 142-148. https://doi.org/10.1111/j.1440-0979.2005.00371.x

Edwards, H., \& Dirette, D. (2010). The Relationship between Occupational Stress and Burnout among Occupational Therapists. Occupational Therapy in Health Care, 24, 119-129. https://doi.org/10.3109/07380570903329610

Escudero-Escudero, A. C., Segura-Fragoso, A., \& Cantero-Garlito, P. A. (2020). Burnout Syndrome in Occupational Therapists in Spain: Prevalence and Risk Factors. Interna- 
tional Journal of Environmental Research and Public Health, 17, 3164.

https://doi.org/10.3390/ijerph17093164

Evers, W. J., Brouwers, A., \& Tomic, W. (2002). Burnout and Self-Efficacy: A Study on Teachers' Beliefs When Implementing an Innovative Educational System in the Netherlands. British Journal of Educational Psychology, 72, 227-244. https://doi.org/10.1348/000709902158865

Graber, R., Pichon, F., \& Carabine, E. (2015). Psychological Resilience. London: Overseas Development Institute.

Gupta, S., Paterson, M. L., Lysaght, R. M., \& von Zweck, C. M. (2012). Experiences of Burnout and Coping Strategies Utilized by Occupational Therapists. Canadian Journal of Occupational Therapy, 79, 86-95. https://doi.org/10.2182/cjot.2012.79.2.4

Hendrickson, B. (1979). Teacher Burnout: How to Recognize It? What to Do about It. Learning, 7, 37-39.

Jackson, D., Firtko, A., \& Edenborough, M. (2007). Personal Resilience as a Strategy for Surviving and Thriving in the Face of Workplace Adversity: A Literature Review. Journal of Advanced Nursing, 60, 1-9. https://doi.org/10.1111/j.1365-2648.2007.04412.x

Kimhi, S., Parmak, M., Boon, H., Sapountzaki, K., Groh, A., \& Ryan, S. (2018). Community and National Resilience and Quality of Life: A Preliminary Cross-Cultural Study. American International Journal of Social Science, 7, 1-11.

Kokkinos, C. M. (2006). Factor Structure and Psychometric Properties of the Maslach Burnout Inventory-Educators Survey among Elementary and Secondary School Teachers in Cyprus. Stress and Health, 22, 25-33. https://doi.org/10.1002/smi.1079

Laschinger, H. K. S., Leiter, M., Day, A., \& Gilin, D. (2009). Workplace Empowerment, Incivility, and Burnout: Impact on Staff Nurse Recruitment and Retention Outcomes. Journal of Nursing Management, 17, 302-311. https://doi.org/10.1111/j.1365-2834.2009.00999.x

Leiter, M. P., \& Harvie, P. L. (1996). Burnout among Mental Health Workers: A Review and a Research Agenda. International Journal of Social Psychiatry, 42, 90-101. https://doi.org/10.1177/002076409604200203

Lloyd, C., \& King, R. (2004). A Survey of Burnout among Australian Mental Health Occupational Therapists and Social Workers. Social Psychiatry and Psychiatric Epidemiology, 39, 752-757. https://doi.org/10.1007/s00127-004-0808-7

Lloyd, C., King, R. \& Bassett, H. (2002). A Survey of Australian Mental Health Occupational Therapists. British Journal of Occupational Therapy, 65, 88-96. https://doi.org/10.1177/030802260206500207

Luthar, S. S. (2006). Resilience in Development: A Synthesis of Research across Five Decades. In D. Cicchetti, \& Cohen (Eds.), Developmental Psychopathology: Risk, Disorder and Adaptations (2nd ed., Vol. 3, pp. 739-795). New York: Wiley. https://doi.org/10.1002/9780470939406.ch20

Maslach, C., \& Jackson, S. E. (1981). The Measurement of Experienced Burnout. Journal of Occupational Behaviour, 2, 99-113. https://doi.org/10.1002/job.4030020205

Maslach, C., \& Jackson, S. E. (1982). Burnout in Health Professions: A Social Psychological Analysis. In G. S. Sanders, \& J. Suls (Eds.), Social Psychology of Health and Illness (pp. 227-251). Hillsdale, NJ: Erlbaum.

Maslach, C., \& Jackson, S. E. (1986). Maslach Burnout Inventory Manual (2nd ed.). PaloAlto, CA: ConsultingPsychologistsPress.

Masten, A. S. (2001). Ordinary Magic: Resilience Processes in Development. American 
Psychologist, 56, 227-238. https://doi.org/10.1037/0003-066X.56.3.227

McGee-Cooper, A., Trammell, D., \& Lau, B. (1990). You Don't Have to Go Home from Work Exhausted: The Energy Engineering Approach. Dallas, TX: Bowen \& Rogers.

National Scientific Council on the Developing Child (2015). Supportive Relationships and Active Skill Building Strengthen the Foundations of Resilience.

Oddie, S., \& Ousley, L. (2007). Assessing Burnout and Occupational Stressors in a Medium Secure Service. The British Journal of Forensic Practice, 9, 32-48. https://doi.org/10.1108/14636646200700011

Ong, A. D., Bergeman, C. S., Bisconti, T. L., \& Wallace, K. A. (2006). Psychological Resilience, Positive Emotions, and Successful Adaptation to Stress in Later Life. Journal of Personality and Social Psychology, 91, 730-749. https://doi.org/10.1037/0022-3514.91.4.730

Painter, J., Akroyd, D., Elliot, S., \& Adams, R. D. (2003). Burnout among Occupational Therapists. Occupational Therapy in Health Care, 17, 63-77.

https://doi.org/10.1080/J003v17n01_06

Poulsen, A. A., Meredith, P., Khan, S. R., Henderson, J., Castrisos, V., \& Khan, A. (2014). Burnout and Work Engagement in Occupational Therapists. British Journal of Occupational Therapy, 77, 156-164. https://doi.org/10.4276/030802214X13941036266621

Reis, H., Vale, C., Camacho, C., Estrela, C., \& Anjos, M. (2018). Burnout among Occupational Therapists in Portugal: A Study of Specific Factors. Occupational Therapy in Health Care, 32, 275-289.

Rivard, A. M., \& Brown, C. A. (2019). Moral Distress and Resilience in the Occupational Therapy Workplace. Safety, 5, 10. https://doi.org/10.3390/safety5010010

Robson, C. (2011). Real World Research: A Resource for Social-Scientists and Practitioner-Researchers (3rd ed.). Oxford: BlackwellPublishing.

Rodger, S., Thomas, Y., Holley, S., Springfield, E., Edwards, A., Broadbridge, J. et al. (2009). Increasing the Occupational Therapy Mental Health Workforce through Innovative Practice Education: A Pilot Project. Australian Occupational Therapy Journal, 56, 409-417. https://doi.org/10.1111/j.1440-1630.2009.00806.x

Rogers, J. C., \& Dodson, S. C. (1988). Burnout in Occupational Therapists. The American Journal of Occupational Therapy, 42, 787-792. https://doi.org/10.5014/ajot.42.12.787

Santos, R. S. (2012). Why Resilience? A Review of Literature of Resilience and Implications for Further Educational Research.

https:/go.sdsu.edu/education/doc/files/01370-ResiliencyLiteratureReview\%28SDSU\%2 9.pdf

Scanlan, J. N., \& Still, M. (2013). Job Satisfaction, Burnout and Turnover Intention in Occupational Therapists Working in Mental Health. Australian Occupational Therapy Journal, 60, 310-318. https://doi.org/10.1111/1440-1630.12067

Scanlon, J., Still, M., Stewart, K., \& Croaker, J. (2010). Recruitment and Retention Issues for Occupational Therapists in Mental Health: Balancing the Pull and the Push. Australian Occupational Therapy Journal, 57, 102-110. https://doi.org/10.1111/j.1440-1630.2009.00814.x

Schlenz, K. C., Guthrie, M. R., \& Dudgeon, B. (1995). Burnout in Occupational Therapists Working in Head Injury Rehabilitation. The American Journal of Occupational Therapy, 49, 986-993. https://doi.org/10.5014/ajot.49.10.986

Sofology, M., Efstratopoulou, M., \& Dunn, T. (2018). Predicting Burnout Syndrome in Greek Mental Health Professionals. Journal of Social Service Research, 45, 1-8. https://doi.org/10.1080/01488376.2018.1480556 
Stephenson, P. (2019). Building Resilience and Minimizing Burnout in School-Based Practice. Journal of Occupational Therapy, Schools, \& Early Intervention, 12, 1-11. https://doi.org/10.1080/19411243.2019.1590754

Waite, A. (2012). Battling Workplace Burnout: Practitioners Discuss Keys to Job Satisfaction and Lower Turnover. Occupational Therapy Practice, 24, 9-12.

Youssef, C. M., \& Luthans, F. (2007). Positive Organizational Behavior in the Workplace: The Impact of Hope, Optimism, and Resilience. Journal of Management, 33, 774-800. https://doi.org/10.1177/0149206307305562 